\title{
UNITED STATES BUILDING CODE APPROACH TO VARIATIONS IN REGIONAL SEISMICITY
}

\author{
Charles A. Kircher ${ }^{1}$ \\ This paper was the keynote address at the NZSEE Technical Conference and AGM \\ held at the Rydges Hotel, Rotorua on 19-21 March 1999
}

SUMMARY

\begin{abstract}
The United States contains regions of greatly varying seismicity ranging from a relatively narrow strip of very high seismicity along coastal California in the West to broad areas of low or moderate seismicity typical of the Central and Eastern United States. The United States currently has three major regional model building codes. While all three codes have traditionally used the concept of seismic zones to identify and distinguish between regions of different seismicity, they have not had a consistent basis for their seismic criteria. Beginning in the year 2000, the three model building codes will merge and become the new International Building Code (IBC) applicable to the whole United States. New seismic design criteria have been developed for the 2000 IBC that now define ground shaking for building design by spectral acceleration contours. This paper describes the background and basis for the new seismic design criteria of the $2000 I B C$, and how these criteria address the large variation in seismic hazard across the United States.
\end{abstract}

\section{INTRODUCTION}

Earthquake design in the United States is currently governed by the seismic provisions of regional model building codes the Uniform Building Code (International Conference of Building Officials, 1997), the National Building Code (Building Officials and Code Administrators International, 1997) and the Standard Building Code (Southern Building Code Congress International, 1997). The Uniform Building Code $(U B C)$ is used throughout most of the western United States where earthquake design is routinely required. The $B O C A$ National Building Code $(N B C)$ and Standard Building Code ( $S B C$ are used in the northeastern and southern states respectively, where seismic design is typically the exception, rather than the rule.

The Seismic provisions of model building codes come primarily from "source" documents. Since the first edition was published in 1960, the Recommended Lateral Force Requirements and Commentary, known commonly as the SEAOC "Blue Book" (Structural Engineers Association of California, 1996) has guided development of the UBC (and indirectly influenced seismic criteria of older editions of the $N B C$ and $S B C$ ). Recent $N B C$ and $S B C$ seismic criteria are now based on the NEHRP (National Earthquake Hazard Reduction Program) Recommended Provisions for the Development of Seismic Regulations for New Buildings, or simply the NEHRP Provisions, (Building Seismic Safety Council, 1995). The NEHRP Provisions also influence the seismic criteria of ASCE 7 - Minimum Design Loads for Buildings and Other Structures (American Society of Civil Engineers), an intermediary step to the $N B C$ and $S B C$. Figure

${ }^{1}$ Kircher \& Associates, Mountain View, California, USA
1 illustrates the relationship of the three model building codes and their primary source documents.

Beginning in the year 2000 , the three regional model building codes will merge into a single model building code for the whole United States - the new International Building Code (International Code Council, 1998). The primary source document for the 200 International Building Code (IBC) is the 1997 NEHRP Provisions (Building Seismic Safety Council, 1998). While the SEAOC "Blue Book" has long enjoyed a leadership role for seismic design criteria, the NEHRP Provisions provide a national, rather than a California, perspective that is considered to be a more appropriate basis for the $I B C$. Beginning with the 1997 edition, the NEHRP Provisions are now the preeminent source of seismic design criteria for all regions of the United States, from regions of very high seismicity in the west to regions of low or moderate seismicity in the central and eastern United States.

Anticipating the new role and importance of the 1997 NEHRP Provisions, code development and research agencies took action to improve the seismic criteria and earthquake design procedures of the provisions. Continuing with work begun in the previous (1994) code cycle, two parallel efforts were undertaken. Along one path, the United States Geological Survey (USGS) was tasked with the development of new seismic hazard maps for the United States. Along the second path, the Seismic Design Procedures Group (SDPG) of the Building Seismic Safety Council (BSSC) was created and tasked with development of criteria and methods appropriate for implementing the new hazard maps in the 1997 NEHRP Provisions. The parallel-path approach 


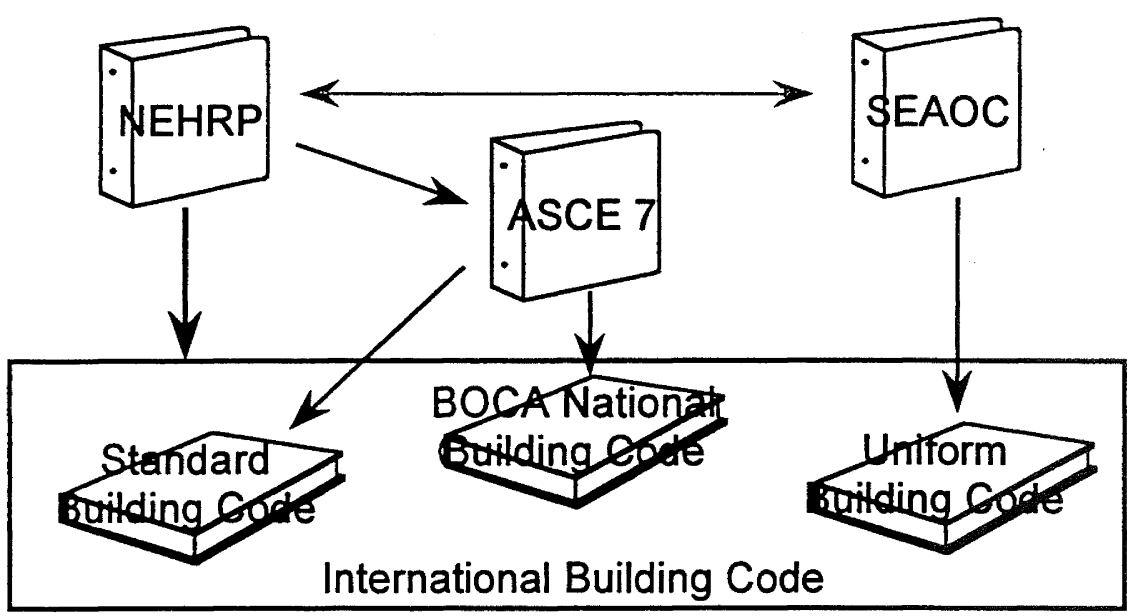

Figure 1: United States Building Codes and Source Documents

permitted earth scientists at the USGS to crate a suite of maps that represent the best scientific knowledge available at the time. Separately, structural and geotechnical engineers of the SDPG developed (and debated) rules for transforming the new "scientific" map data into seismic design criteria appropriate for inclusion in building codes. The division of earth science and engineering efforts was essential to the successful development of the new seismic design criteria of the 1997 NEHRP Provisions (and 2000 IBC).

\section{UNITED STATES SEISMICTY}

This paper will provide an engineering perspective on the development of the new seismic design criteria of the 1997 NEHRP Provisions, rather than serve as an in-depth discussion of earth science issues. ${ }^{1}$ A brief description of key aspects of United States seismicity is provided in this section as background for subsequent discussions of the new seismic design criteria, and the rationale used by SDPG to develop these criteria. Readers desiring a more thorough treatment of United States seismicity may wish to consult references such as An Introduction to the Seismicity of the United States (Algermissen, 1983). A detailed description of the hazardanalysis methods and seismicity data used by the USGS to develop the new hazard maps may be found in "National Seismic-Hazard Maps" Documentation June 1996" USGS Open-File Report 96-532 (Frankel, et al., 1996). This report and other data may be found on the Internet World Wide Web (http://geohazards.cr.usgs.gov/eq/).

The United States may be crudely divided into two basic seismic regions: the western United States (WUS) region and the central and eastern United States (CEUS) region. The boundary between WUS and CEUS regions is located along the eastern edge of the Basin and Range province as shown in Figure 2. Figure 2 also shows faults and fault segments of the WUS region.
In very simple terms, fault activity (and knowledge of fault properties) distinguishes WUS and CEUS regions. The WUS region has a large number of faults or fault segments (over 500) for which slip rates and maximum magnitudes are known. These faults dominate the seismic hazard calculation in areas of high and moderate seismicity in the WUS region. In contrast, the CEUS region has relatively few known faults, and seismicity is primarily a function of background zones that quantify hazard in areas with limited historic activity. The CEUS region also includes a few special zones of seismicity where large-magnitude earthquakes can occur, or have occurred, such as the 1811 - 1812 New Madrid sequence in the Mississippi Valley and the 1886 Charleston, South Carolina earthquake.

The geology of the WUS region is characterized by typical "firm-rock" conditions with a shear wave velocity of 760 $\mathrm{mm} / \mathrm{sec}$ in the top 30 meters. The crust in the CEUS region is typically much harder, characterized by "hard-rock" conditions with a shear wave velocity in the thousands of meters per second. Attenuation models are quite different for WUS and the CEUS regions, reflecting differences in both the underlying geology as well as the methods used to estimate ground shaking. Attenuation functions of the WUS region are based on empirical data that are sufficient to permit statistical evaluation of strong-motion records. Only limited recorded data exists for the CEUS region, and attenuation functions are based on theoretical models and stochastic simulations.

CEUS attenuation models predict ground shaking that is typically stronger and attenuates less rapidly than that of WUS attenuation models. The difference between CEUS and WUS attenuation is most significant at longer response periods and for larger magnitude events. For example, Figure 3 compares WUS and CEUS attenuation functions for a magnitude M7.25 event. At about $10 \mathrm{~km}$ from the source, 1 -second spectral response at a CEUS site is expected to be about twice that of a comparable WUS site. CEUS attenuation models also predict more high-frequency ground 
shaking than that of WUS attenuation models. Typically, the peak of a WUS response spectrum occurs at a period between about 0.2 and 0.4 seconds, while the peak of about 0.1 second, or less.

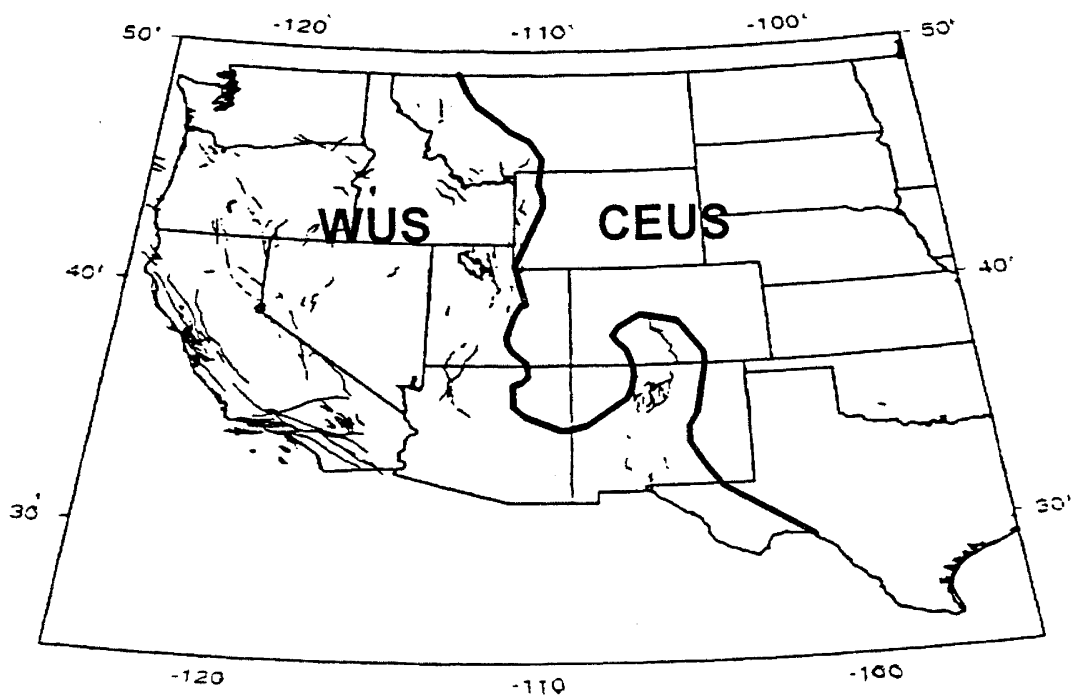

Figure 2: Boundary between WUS and CEUS Regions.

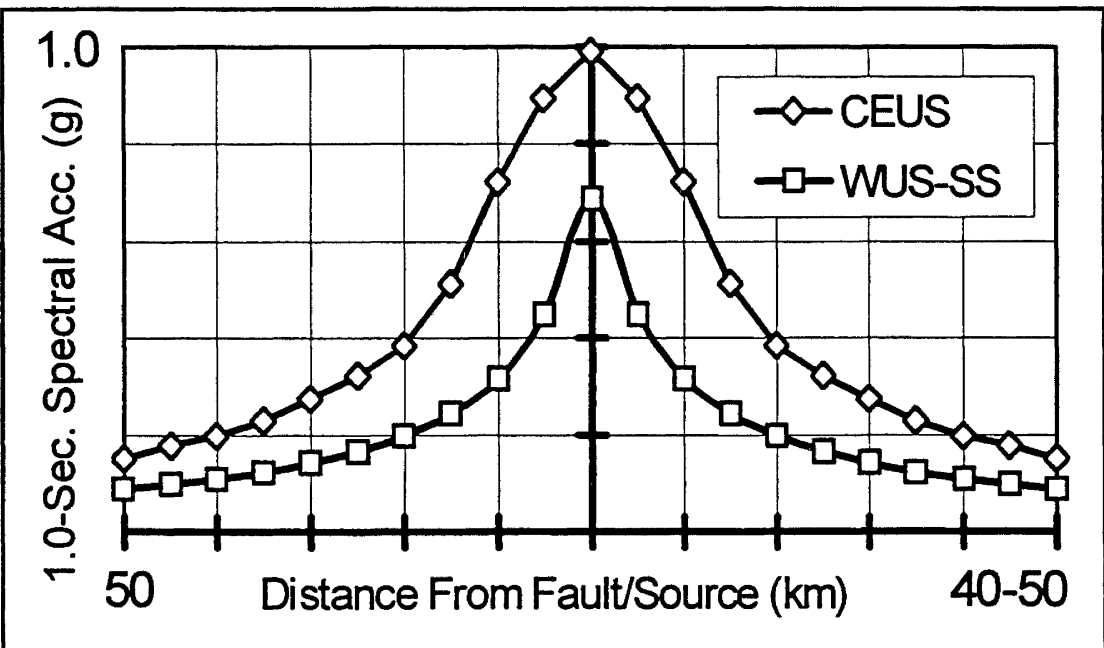

Figure 3: CEUS and WUS (Strike-Slip) Attenuation - Magnitude M7.25 Event

While earthquakes generally occur less frequently in the CEUS than in the WUS, the large-magnitude events can and do occur in the CEUS region. In fact, the New Madrid sequence of $1811-1812$ and the 1886 Charleston earthquake represent the two largest events of historical record in the continental United States. It is this variation I WUS and CEUS seismicity that posed the greatest challenge to the development of consistent seismic design criteria for the whole United States. How should hazard be defined such that the ground shaking is representative of earthquakes likely to occur in regions of high seismicity (such as coastal California), without understating the rare, large-magnitude event that can occur in regions of low or moderate seismicity (such as Charleston, South Carolina)?

\section{HAZARD CURVES}

Regional differences in the rate of earthquake occurrence and attenuation are quantified by hazard curves that describe the level of ground shaking as a function of the annual frequency of exceedance (i.e. the inverse of the return period). As a necessary step in their mapping work, the USGS calculated hazard curves for about 150,000 sites located on a grid of points geographically distributed throughout the United States. At grid points, spectral response was attenuated from contributing sources and aggregated into a hazard curve for each response period of interest. Hazard curves were calculated for several different response periods to permit construction of site response spectra. Site response was based on a consistent assumption of "firm-rock" conditions for all WUS and CEUS sites. 
Trends in hazard curves reveal fundamental differences in regional seismicity. For example, Figure 4 provides a comparison of hazard at specific Zip Code locations in nine major United States cities: San Francisco, Los Angeles, Seattle, Salt Lake City (in the WUS region) and Memphis, Charleston, St. Louis, New York City and Chicago (in the CEUS region). Zip Code locations correspond to sites geographically located near the civic center of each city (e.g. near San Francisco City Hall). Figure 5 is a copy of one of the probabilistic seismic hazard maps developed by the USGS that also shows the location of major United States cities.
In Figures 4 and 5, spectral acceleration is calculated at a response period of 1 second. For reference, the 1997 UBC bases the design of 1-second structures located on firm rock in Seismic Zone 4 not near an active source on a 1-second spectral acceleration of $0.4 \mathrm{~g}$. Very close to highly active faults, "Near-Source" factors of the 1997 UBC double this level of spectral acceleration (e.g. $0.8 \mathrm{~g}$ for design of structures located on firm rock close to the San Andreas Fault).

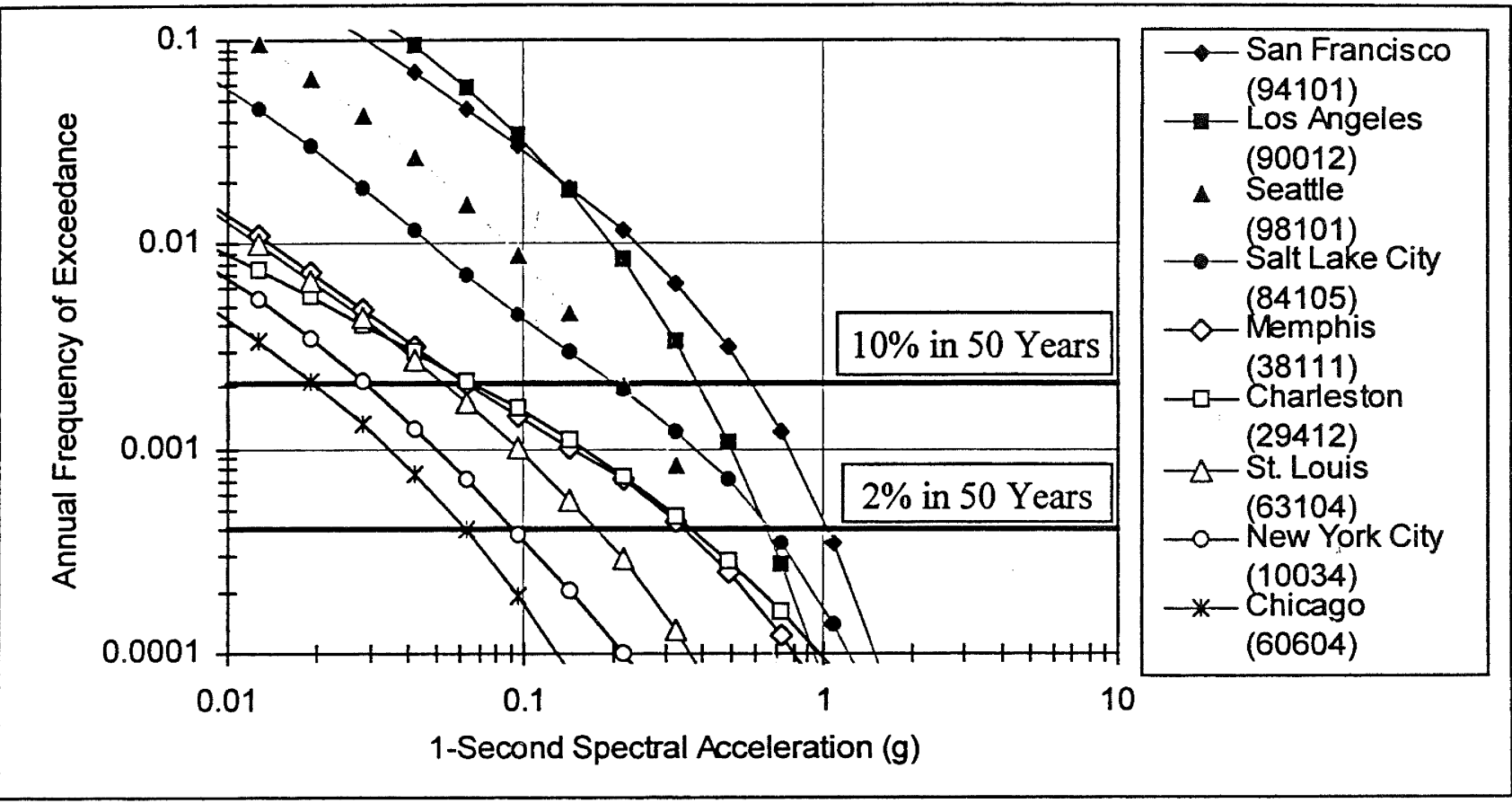

Figure 4: Hazard Curves for Selected United States Cities and Zip Codes - (USGS, 1996)

Comparing hazard curves for Memphis and Charleston, CEUS cities that have felt strong ground shaking due to rare large-magnitude earthquakes, with hazard curves for Los Angeles and San Francisco, WUS cities of high seismicity, indicates a significant difference in the slopes of WUS and CEUS hazardous curves. The slopes of the hazard curves greatly affect the relative amount of CEUS and WUS ground shaking at different return periods. For example, at an annual frequency (of exceedance) of 1 in 100, Memphis ground shaking is over an order of magnitude less than Los Angeles ground shaking. At an annual frequency of 1 in 1,000, Memphis ground shaking is about 4 times less than Los Angeles ground shaking. But at an annual frequency of 1 in 10,000 , Memphis ground shaking is about the same as Los Angeles ground shaking.

The traditional $10 \%$ in 50 year (approximate 500 -year return period) definition of the Design description of strong ground shaking in zones of high seismicity, but does not adequately define ground shaking in zones of low seismicity where rare, large-magnitude earthquake can occur.

\section{MAXIMUM CONSIDERED EARTHQUAKE}

The 1994 NEHRP Provisions (and prior editions) base design parameters on the Design Earthquake, the "earthquake that produces ground motions at the site under consideration that have a 90 percent probability of not being exceeded in 50 years." While the 1994 NEHRP Provisions also define a Maximum Capable Earthquake (MCE), the MCE is only required for checking displacement capacity and stability of base isolation systems. For properly designed conventional structures, the 1994 NEHRP Provisions implicitly assumed that beyond Design Earthquake ground shaking could be sustained by the structure without collapse, but perhaps with reduction in performance. This is a reasonable assumption in zones of high seismicity, where MCE ground shaking would not be expected to be more than about $50 \%$ higher than that 
of the Design Earthquake. This assumption is not appropriate in zones of low seismicity, where MCE ground shaking could be 3 to 4 times higher than that of the Design Earthquake.

For the 1997 NEHRP Provisions, the SDPG proposed a new approach for seismic design values - design all structures (conventional as well as isolated) for ground shaking corresponding to the Maximum Considered Earthquake (MCE). That is, explicitly design structures using procedures that protect against collapse for MCE ground shaking. This approach extends the probabilistic definition of the hazard from $10 \%$ in 50 years (approximate 500-year return period) previously used for Design Earthquake to $2 \%$ in 50 years (approximate 2,500-year return period) for the new MCE. The use of a probabilistic MCE defined by a $2 \%$ in 50 -year hazard level better estimates ground shaking of rare, large magnitude earthquakes in the CEUS that can have return periods on the order of 1,000 to 5,000 years.

Extending the return period of the earthquake to approximately 2,500 years better captures rare events in regions of low or moderate seismicity, but can be overly conservative in regions of high seismicity. In regions of high seismicity, the return period of large-magnitude earthquakes is typically on the order of hundreds of years, rather than thousand of years. To achieve a $2 \%$ in 50 -year probabilistic goal in regions of high seismicity, the ground shaking must effectively bound ground motion variability at 2 to 3 standard deviations (e.g., a level of ground shaking to 5 times the median). Probabilistic estimates produce an extremely high level of ground shaking at sites close to highly active faults (i.e., faults with a high slip rate). In such cases, a deterministic estimate of MCE ground shaking is used in lieu of the probabilistic calculation of hazard.

The deterministic estimate of MCE ground shaking has two components. First, MCE ground shaking is limited to 1.5 times the level of ground shaking that has traditionally be used for building design in zones of high seismicity (e.g., 1.5 times "Seismic Zone 4" criteria of the 1994 UBC), unless the site is close to a highly active fault. Second, when close to a highly active fault, MCE ground shaking is based on 1.5 times the median level of ground shaking corresponding to the "maximum magnitude" earthquake on the nearby source. The 1.5 factor is approximately equal to 1 standard deviation of ground motion variability.

These somewhat complex rules acknowledge that properly designed buildings have generally performed well in past earthquakes, except when located very close to fault rupture. The deterministic limits only affect MCE ground shaking in regions of very high seismicity (e.g. coastal California), typically at sties within about 10 to $15 \mathrm{~km}$ of a highly active fault. Away from highly active faults or in regions of low or moderate seismicity, ground shaking is governed by the probabilistic $(2,500$ year return period) definition of the MCE.

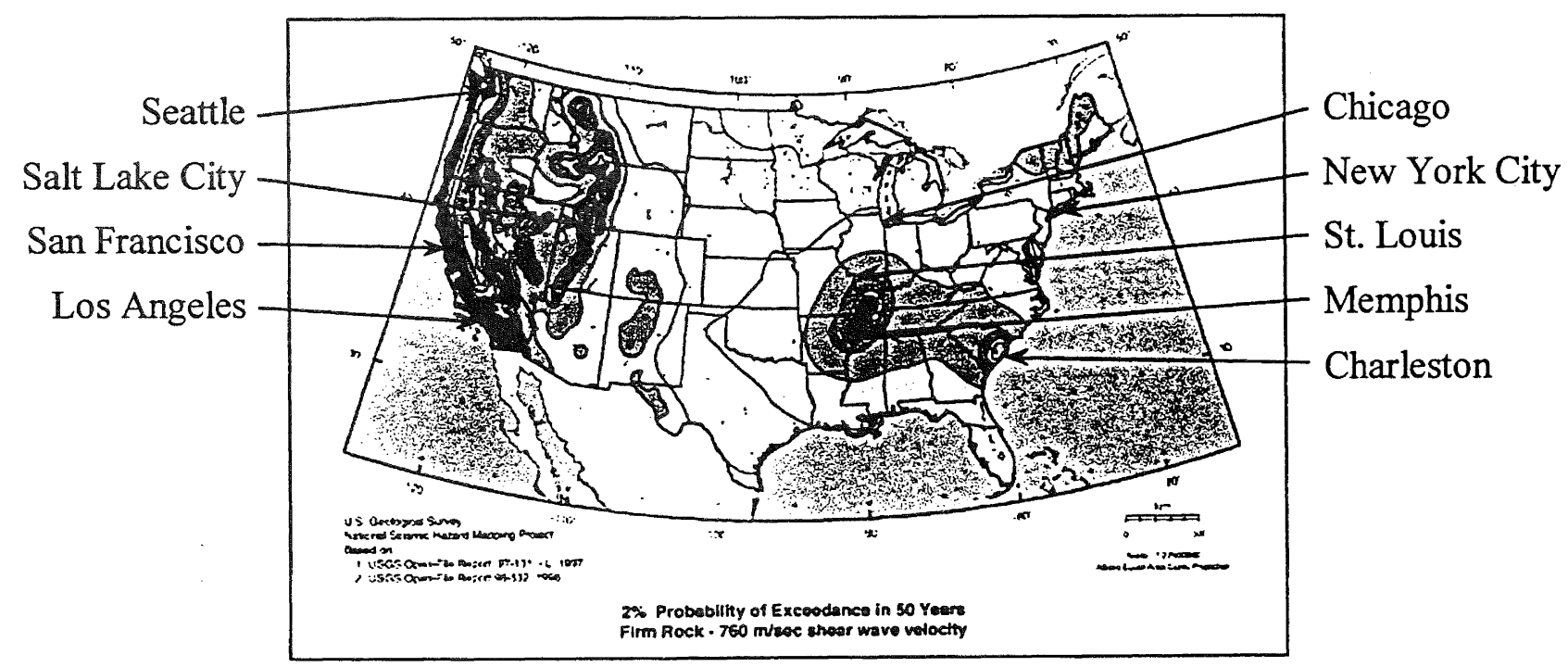

Figure 5: Probabilistic Seismic Hazard Map - 1.0-Second Spectral Acceleration Response (USGS, 1996) 


\section{DESIGN EARTHQUAKE}

It would be convenient to use the MCE ground shaking directly in design of structures, but other terms and factors of the 1997 NEHRP Provisions (and 2000 IBC) are based on Design Earthquake ground shaking. For compatibility with existing terms and factors, MCE ground shaking is factored by $2 / 3$ to obtain Design Earthquake ground shaking. Future modifications to the 00 NEHRP Provisions (and 2003 IBC) will likely eliminate the Design Earthquake terminology by adjusting other factors, so that MCE ground shaking can be used directly for design. Such changes would be made to simplify design equations, but would not change the stiffness or strength of the structure.

Figure 6 illustrates Design Earthquake criteria for spectral acceleration at a response period of 1 second. The horizontal axis indicates distance from a (hypothetical) major seismic source (highly active fault). At short distances ground shaking is dominated by the nearby source. As distance from the source increases, the level of ground shaking decreases, and the contribution to site hazard from other faults and background sources increases.

The $2 / 3$ factor used to develop Design Earthquake ground shaking from MCE ground shaking has the following implications. First, the return period of Design Earthquake ground shaking varies geographically due to differences in the slopes of hazard curves (and the affects of the deterministic limits on the MCE for sites near highly active sources). In regions of low seismicity the effective return period of Design Earthquake ground shaking is typically about 1,000 to 1,500 years. In regions of high seismicity, but not near a highly active source, the effective return period drops to about 500 years (consistent with previous code criteria). Near a highly active source, the effective return period typically drops below 500 years and converges on the return period of the deterministic "maximum-magnitude" earthquake (e.g., return period of characteristic earthquake). Some of the more active faults in California have characteristic-earthquake return periods of a couple of hundred years.

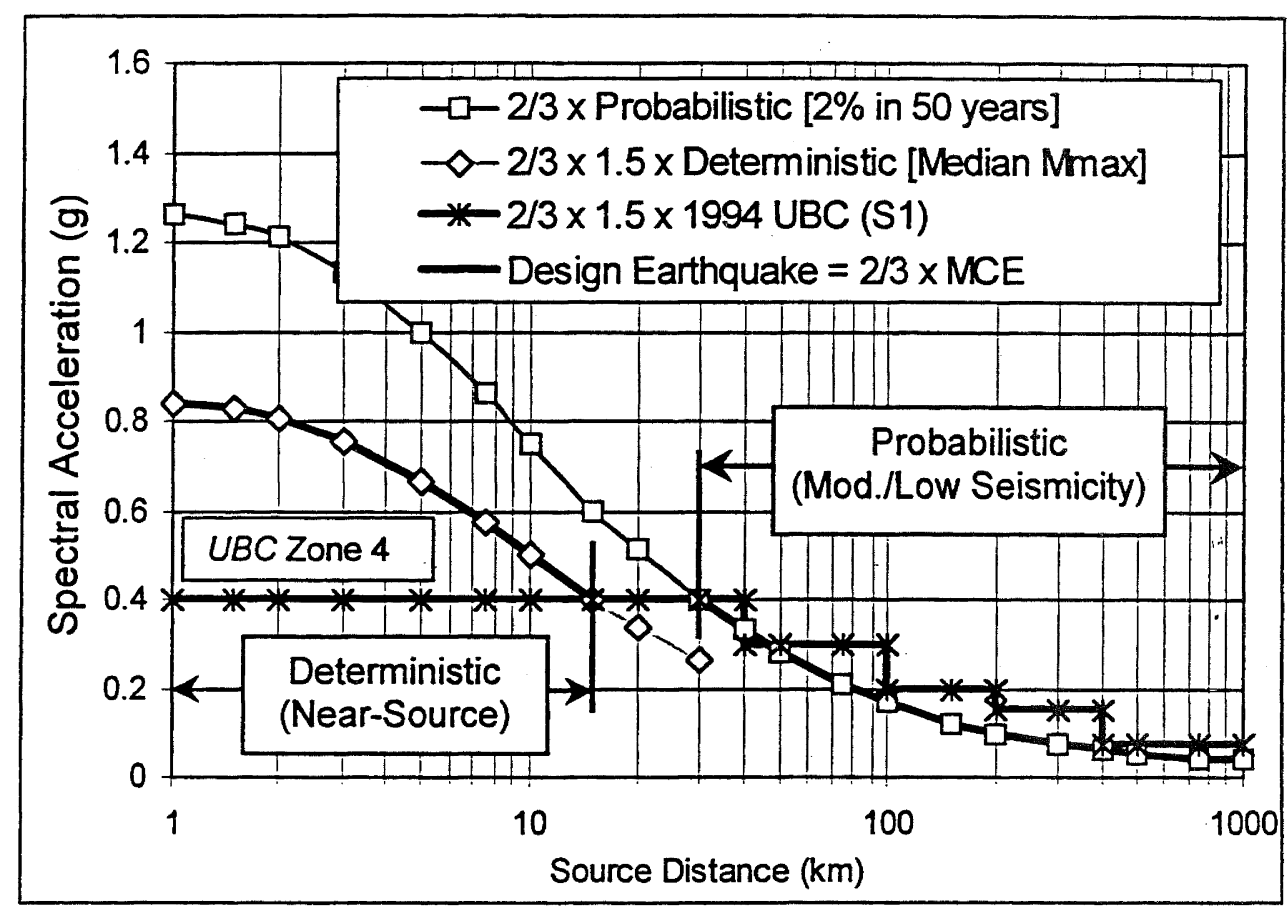

Figure 6: Design Earthquake Criteria - 1-Second Spectral Acceleration (2000 IBC)

The application of the $2 / 3$ factor intentionally balances the 1.5 factor of the deterministic MCE. Close to active faults, Design Earthquake ground shaking is effectively based on the median attenuation of the deterministic "maximummagnitude" earthquake. Basing Design Earthquake ground shaking on median attenuation is consistent with the theory used to develop the near-source factors of the 1997 UBC (Kircher, 1998). Beginning with the 1997 edition, the $U B C$ now requires structures located in Seismic Zone 4 near active faults to be designed with a near-source factor. The nearsource factor increases design earthquake force as a function of fault proximity, in a manner similar to the increase in the spectral acceleration shown in Figure 6 for the deterministic (near-source) region.

\section{DESIGN SPECTRA AND SITES FACTORS}

Design earthquake response spectra (design spectra) of the 1997 NEHRP Provisions (2000 IBC) are constructed using a standard two-domain spectrum shape as shown in Figure 7. A domain of constant spectral acceleration defines the spectrum shape at short periods and at long-periods the 


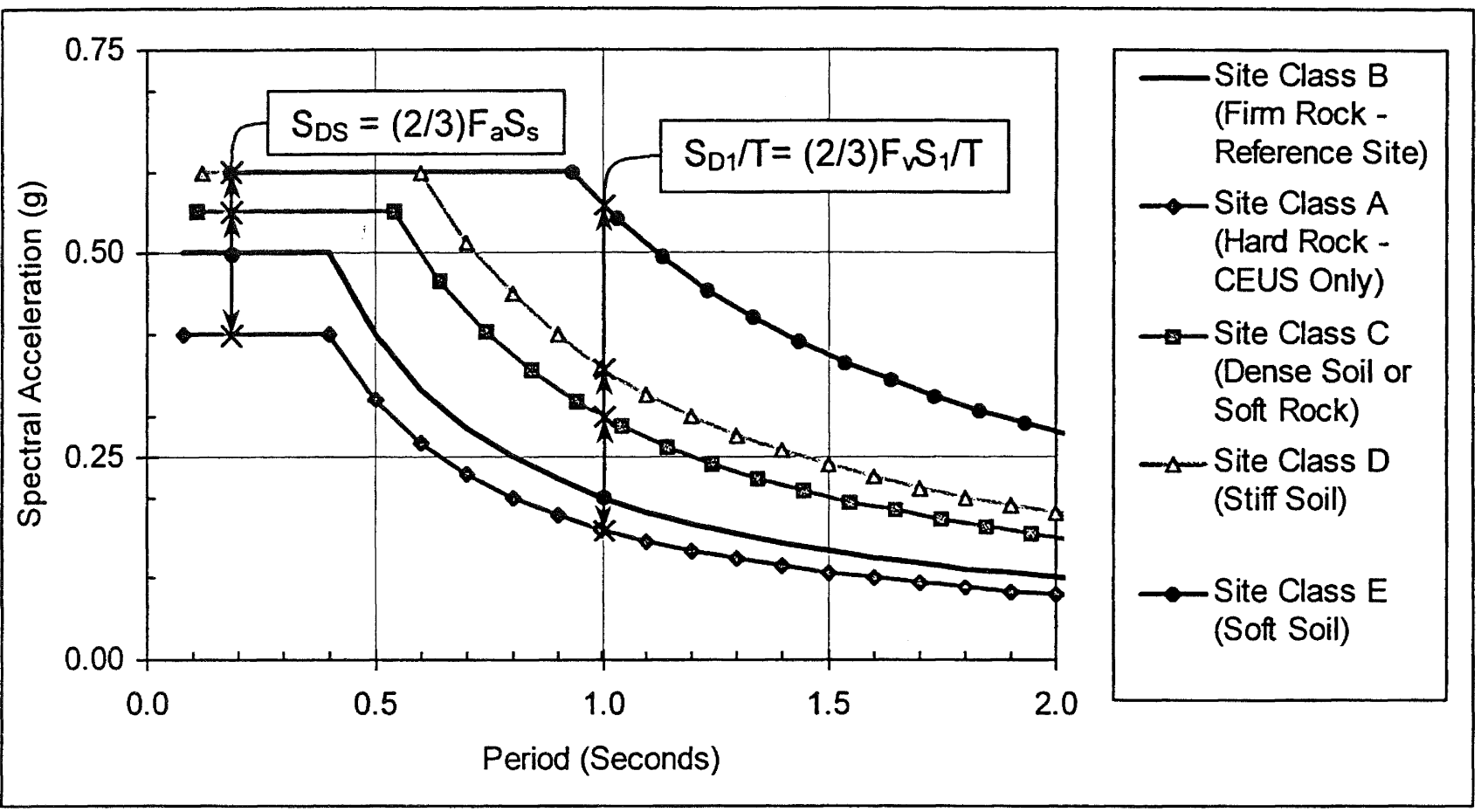

Figure 7: Example Construction of Design Spectra for Site Classes A, B, C, D and E

spectrum shape is defined by a domain of constant spectral velocity (i.e., spectral acceleration divided by response period).

The acceleration plateau is based on mapped values of MCE spectral acceleration. $S_{s}$, calculated at a response period of 0.2 seconds for reference (firm-rock) site conditions. A response period of 0.2 seconds captures short-period ground shaking for both CEUS and WUS sites. The velocity domain is based on mapped values of MCE spectral acceleration, $S_{1}$, calculated at a response period of 1 second for reference (firm-rock) site conditions. Design spectrum acceleration coefficients, $S_{D S}$ and $S_{D 1}$, are obtained by factoring MCE spectral accelerations by two-thirds and by site factors, $\mathrm{F}_{\mathrm{a}}$ and $\mathrm{F}_{\mathrm{v}}$, respectively.

Site/soil amplification factors $F_{a}$ and $F_{v}$ are a function of site class that distinguishes between various rock and soil profiles based on the shear wave velocity in the top $30 \mathrm{~m}$ of material (and other criteria). Site factors are 1.0 for Site Class B (firm rock), since this is the reference site class used by the USGS to develop MCE special contour maps. This site factor is 0.8 for Site Class A, effectively reducing response for hard-rock sites in CEUS.

Site factors for Site Classes C, D and E are amplitudedependent due to soil "non-linearity," typically specifying greater amplification lower levels of shaking. The site/soil amplification factors distinguish between acceleration and velocity, typically specifying greater amplification in the velocity domain. Figure 7 illustrates trends in site/soil amplification for a moderate level of ground shaking (i.e. peak ground acceleration of about $0.2 \mathrm{~g}$ - firm-rock site conditions).
As an example of the variation in seismic criteria across the United States, design spectra are calculated and plotted in Figure 8 for each of nine major cities shown in Figure 5. In all cases, design spectra assume stiff soil conditions (Site Class D), the default soil type. Like the hazard curves shown in Figure 4, design spectra are based on specific Zip Code locations that correspond roughly to the civic center of each city.

Precise geographical location of the site is important for accurate calculation of design spectra, particularly for sites near active faults where MCE map contours of spectral acceleration are closely spaced. For example, at long-periods the design spectrum at the San Andreas Fault is over 2 times greater than the design spectrum of the San Francisco site (near the civic center), even though the civic center site is only about $10 \mathrm{~km}$ from the fault.

Salt Lake City has the largest design spectrum of the nine cities. This somewhat surprising result (at least for California engineers) is again due to fault proximity. The Zip Code used to assess Salt Lake City hazard is centered almost directly over a segment of the Wasatch Fault. Downtown Los Angeles and San Francisco sites are located $5 \mathrm{~km}$ to 10 $\mathrm{km}$ from active faults.

\section{SUMMARY AND CONCLUSION}

The $2000 I B C$ and its source document, the 1997 NEHRP Provisions, contain new seismic design criteria that are based on spectral contour maps of MCE ground shaking throughout the United States. These maps and the associated design 
procedures of the $2000 I B C$ address the large variation in seismicity across the United States by using long return period probabilistic criteria in regions of low or moderate seismicity and deterministic criteria near highly active faults in regions of high seismicity. Long return-period probabilistic criteria capture rare, large-magnitude events of the CEUS. Deterministic criteria avoid undue conservatism in regions of high seismicity in the WUS.

\section{REFERENCES}

Algermissen, S.T. 1983. An Introduction to the Seismicity of the United States,. (Oakland, CA: Earthquake Engineering Research Institute).

American Society of Civil Engineers. 1996. Minimum Design Loads for Buildings and Other Structures. ASCE 7. 95. (Washington, D.C.: ASCE).

Buildings Officials and Code Administrators International 1997. The BOCA National Building Code. (Country Club Hills, IL:BOCA).

Federal Emergency Management Agency. 1995. NEHRP Recommended Provisions for Seismic Regulations for New Buildings. (Washington, D.C.: FEMA 222/223).
Federal Emergency Management Agency. 1998. NEHRP Recommended Provisions for Seismic Regulations for New Buildings and Other Structures. (Washington, D.C.:FEMA302/30).

Frankel, Arthur et al. 1996. "National Seismic-Hazard Maps: Documentation June 1996". Open-File Report 96532. (Denver, CO: U.S. Geological Survey).

International Code Council. 1998. International Building Code (Final Draft), (Birmingham, AL:ICC).

International Conference of Building Officials. 1997. 1997 Uniform Building Code. (Whittier, CA:ICBO).

Kircher, Charles A. 1998. "New Ground Shaking Design Criteria." Structural Engineering World Wide 1998, Structural Engineers World Congress, July 18-23, 998, San Francisco, CA (New York, NY:Elsevier).

Seismology Committee of the Structural Engineers Association of California. 1996. Recommended Lateral Force Requirements and Commentary. (Sacramento, CA:SEAOC).

Southern Building Code Congress International, 1997. Standard Building Code. (Birmingham, $\mathrm{AL}: \mathrm{SBCCI}$ ).

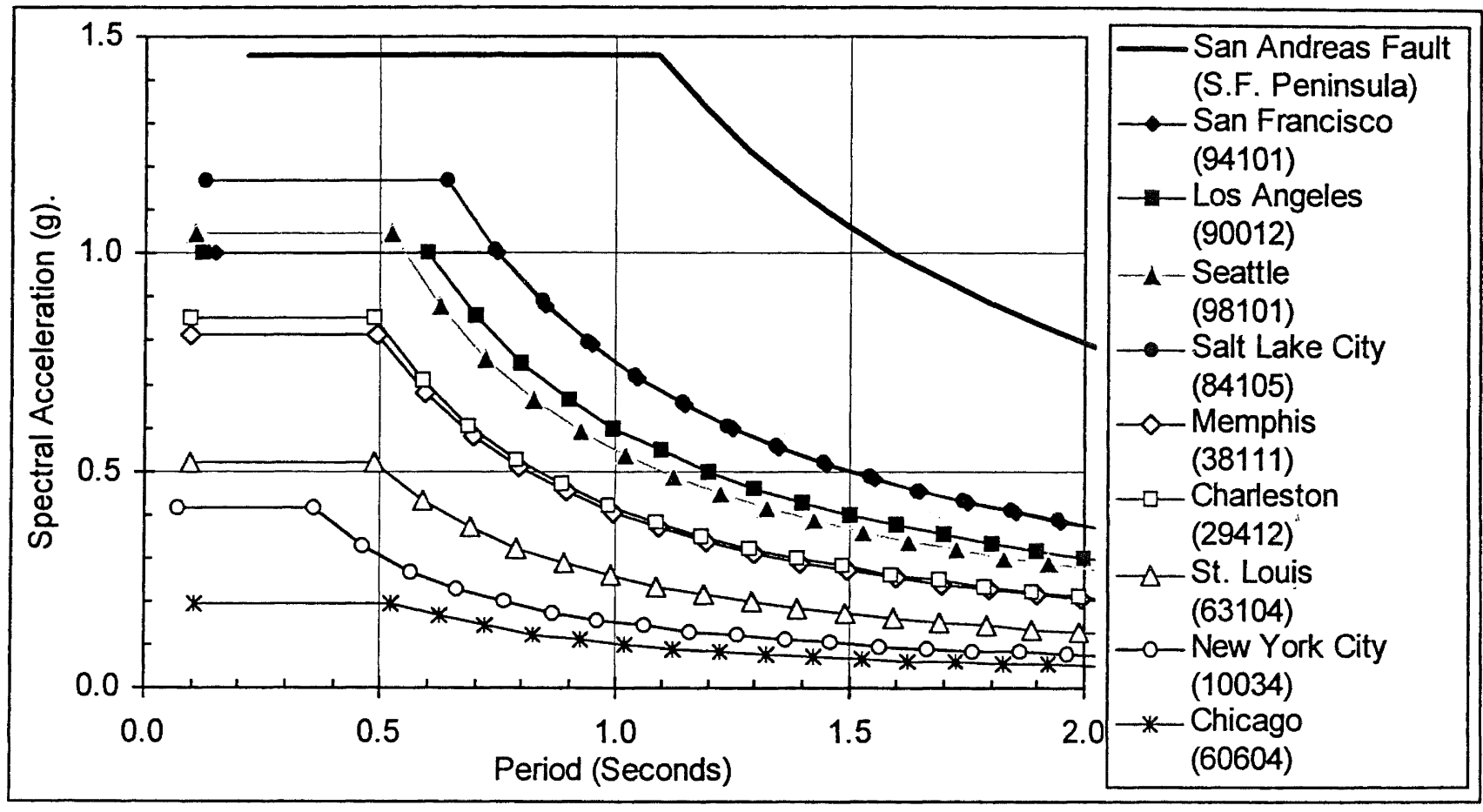

Figure 8: Design Spectra for Selected United States Cities and Zip Codes - Site Class D (Stiff Soil). 